\title{
REVIEW
}

\section{Leaf Trichomes as an Effective Structure for Disease Resistance: The Case of Grapevine Downy Mildew}

\author{
Atsushi KONO** and Takeo SHIMIZU \\ Division of Grape and Persimmon Research, Institute of Fruit Tree and Tea Science, National \\ Agriculture and Food Research Organization, Higashi-Hiroshima, Japan
}

\begin{abstract}
Leaf trichomes confer pest resistance. Dense trichomes could also present a physical barrier to microorganisms, such as grapevine downy mildew caused by Plasmopara viticola on grape. Zoospores of $P$. viticola swim in water and enter stomata. Some wild Vitis accessions such as $V$. labrusca and $V$. cinerea have highly hydrophobic, dense, prostrate trichomes on the lower leaf surface that repel water and enhance resistance to downy mildew. Quantitative trait loci for leaf trichome density have been identified on LGs 5, 7, 8, and 15 of grapevine. A major locus on LG 5 was found in V. vinifera 'Muscat of Alexandria,' which has few leaf trichomes. Hairless alleles on LG 5 in historical $V$. vinifera cultivars reduce trichome density in the progeny of V. labrusca origin. Applying information on these loci in breeding programs would allow the introduction of this natural physical barrier against pathogenic microorganisms into cultivars.
\end{abstract}

Discipline: Horticulture

Additional key words: preexisting disease resistance, Plasmopara viticola, Vitis labrusca, Vitis vinifera

\section{Introduction}

Leaf hairs are termed trichomes from the Greek word for hair-trichos (Hülskamp 2004). Trichomes are historically well-known for conferring pest resistance (Levin 1973), such as against the potato leafhopper (Empoasca fabae) (Poos 1929, Poos \& Smith 1931). The hooked trichomes of Passiflora adenopoda act as a highly efficient defense mechanism against butterfly larvae by hooking into the larval prolegs (Gilbert 1971). In grapevines, the abundance of the predatory mite Typhlodromus pyri was significantly associated with a quantitative trait locus (QTL) having a major effect on the density of leaf trichomes (Barba et al. 2019). Trichomes can also protect plants against UV-B irradiation and freezing (Hülskamp 2004, Johnson 1975, Karabourniotis et al. 1995, Łaźniewska et al. 2012). Trichomes could also play a role in plant-microbe interactions. This review focuses on the effect of leaf trichomes on resistance to grapevine downy mildew (DM) and on QTLs for leaf trichome density, with examples of other crops.

\section{Grapevine downy mildew}

Grapevine is an important crop with worldwide economic importance. Vitis vinifera $\mathrm{L}$. is commercially the most important. It is derived from $V$. vinifera $\mathrm{L}$. ssp. sylvestris, a wild species indigenous to Transcaucasia (Olmo 1976) and the Mediterranean region (ArroyoGarcía et al. 2006, Grassi et al. 2003). During the 19th century, several grape pathogens, notably DM and powdery mildew, were introduced from North America into Europe, where those pathogens caused serious losses in V. vinifera production (Muganu \& Paolocci 2013, Reisch et al. 2012). Many crosses between $V$. vinifera and wild species have been made to develop disease-resistant

\footnotetext{
Present address:

${ }^{1}$ Agriculture, Forestry and Fisheries Research Council, Ministry of Agriculture, Forestry and Fisheries

*Corresponding author: akono@affrc.go.jp

Received 17 December 2019; accepted 5 March 2020.
} 
cultivars (Eibach \& Töpfer 2014, Reisch \& Pratt 1996). Among them, interspecific hybrids with $V$. labrusca parentage produced in the United States, Japan, and other countries can be grown successfully in a wide area of Japan (Yamada \& Sato 2016). These hybrids are sometimes collectively referred to as $V$. labruscana Bailey (Bailey \& Bailey 1930).

Among the pathogens of grapevines, grapevine DM (Fig. $1 \mathrm{~A}, \mathrm{~B}$ ) is one of the most economically damaging diseases and causes serious production losses in Japan (Watauchi et al. 2015). Plasmopara viticola is the causal organism of grapevine DM, and the infection process always takes place in water (Lafon \& Bulit 1981). The oomycete produces zoospores, which swim to stomata on leaves or other green parts. At least $27 \mathrm{DM}$ resistance loci named Rpv (Resistance to Plasmopara viticola) have been identified (Julius Kühn-Institut 2019). In addition, some Pathogenesis-related (PR) genes are induced after DM infection. The defense-related gene $P R-2$ was induced in 'Shine Muscat' and the rootstock cultivar 'Kober 5BB,' but not in the susceptible 'Katta Kurgan' (Shimizu et al. 2019), and the synthesis of most PR-10 defense-related proteins increased significantly 24 to 96 $\mathrm{h}$ after inoculation (Milli et al. 2012). In contrast to these induced resistance responses, leaf trichomes provide a preexisting resistance mechanism against grapevine DM.

\section{Trichomes as an effective structure for disease resistance}

A thick mat of hairs may reduce infection by repelling water (Agrios 2005). Such dense non-glandular trichomes could present a physical barrier to pathogenic fungi or bacteria (Karabourniotis et al. 2019, Łaźniewska et al. 2012). In grapevines, stomata are formed on the lower surface of leaves (Dürinig 1980), where DM infection takes place exclusively. Two main types of trichomes in Vitis are documented: non-glandular and glandular. Among non-glandular trichomes, ribbon and simple trichomes are found on different vegetative organs (Ma et al. 2016). Trichomes on the lower leaf surface are often important in species identification in the family Vitaceae (Gerrath et al. 2015). Ribbon trichomes, the main structures that prevent DM infection, are twisted, greatly elongated, and unicellular. Thick hydrophobic trichomes on the lower surface repel water effectively, and Staudt \& Kassemeyer (1995) showed that wild species with dense trichomes lost resistance after removal of the trichomes. Kortekamp et al. (1999) proposed that these dense trichomes enhance resistance to DM and showed that less force was necessary for removing water droplets from hairy wild species, such as $V$. labrusca and
V. cinerea, than from non-hairy grapevines (Kortekamp et al. 1999).

Vitis labrusca is one source of the dense trichomes in hybrid grapes, and its trichomes make its lower leaf epidermis almost invisible (Gerrath et al. 2015). Its $V$. labruscana descendants, usually with more leaf trichomes than $V$. vinifera, are important cultivars for the breeding of table grapes in Japan (Yamada \& Sato 2016). In Figure 1, C-H show leaf trichomes and their effects on DM infection of a hairy V. labruscana ('Campbell Early') and a glabrous $V$. vinifera ('Muscat of Alexandria'), and two descendants. This relationship between leaf wettability and pathogen invasion has been noted in other plant-pathogen interactions, such as maize (Zea mays) - Puccinia polysora and strawberry (Fragaria $\times$ ananassa) Phytophthora cactorum (Hollier \& King 1985, Reynolds et al. 1989). Vitis labrusca and Vitis cinerea are suggested to have other defense mechanisms as well (Kortekamp \& Zyprian 1999). In contrast, sparse trichomes are associated with susceptibility to bacteria or fungi (Kim 2019). Anthracnose of tea (Camellia sinensis) is caused by Discula theae-sinensis, which invades tea plants through dispersed foliar trichomes (Hamaya 1982, Yamada \& Sonoda 2014).

\section{Inheritance of leaf trichome density and QTLs}

Trichome inheritance has been studied in the racenonspecific resistance of the common bean (Phaseolus vulgaris) to Uromyces appendiculatus var. appendiculatus (Shaik 1985), and genetic variation in leaf trichomes on the lower surface was detected among cultivars and lines (Zaiter et al. 1990). Segregation for hairiness versus hairlessness indicates that trichome density is determined by a single major gene or by duplicate recessive epistatic genes, depending on the cross used.

Recently, the inheritance of grapevine leaf trichomes and the associated QTLs were revealed. QTLs for leaf trichome density were identified on linkage groups (LGs) 5 and 8 from a hybrid wine grape, 'Horizon' (Divilov et al. 2017). Divilov et al. (2018) performed a detailed analysis using two $\mathrm{F}_{1}$ families, Vitis rupestris $\times$ 'Horizon' and 'Horizon' $\times V$. cinerea, and showed that the physical locations of QTLs on LGs 7, 8, and 15, but not LG 5, had an effect on leaf trichome density. A major QTL for leaf trichome density on LG 5, named Leaf Hairs 1 (LHI), explaining $71.9 \%-78.5 \%$ of the phenotypic variance, was identified in a population of $V$. vinifera 'Muscat of Alexandria' $\times V$. labruscana 'Campbell Early' (Kono et al. 2018; Fig. 2 A). Its effect was confirmed in two other populations, and the historical $V$. vinifera cultivars 'Muscat of Alexandria,' 'Katta Kurgan' and 'Parkent' 

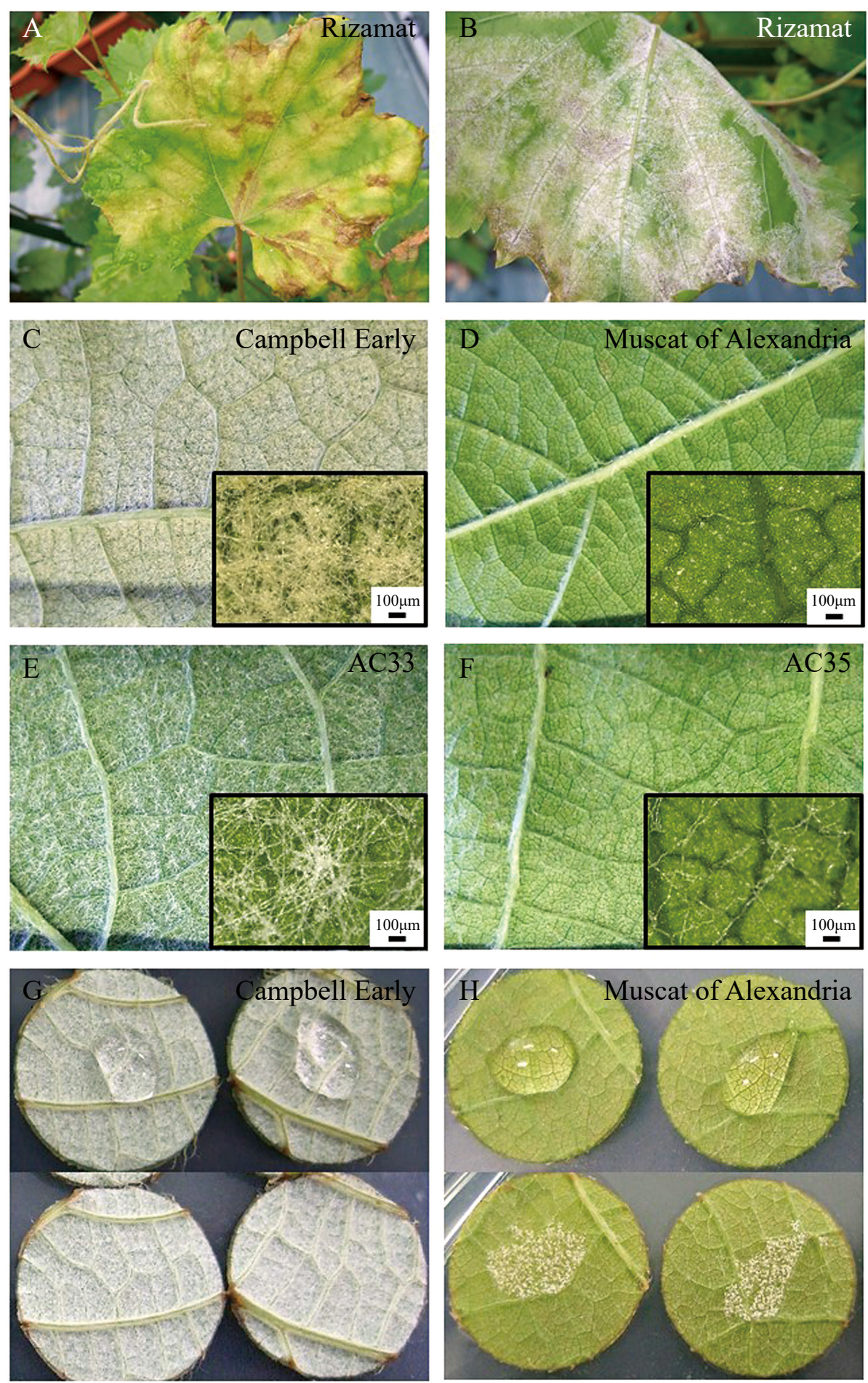

Fig. 1. Symptoms of grapevine downy mildew and underside leaf trichomes in grapevines A, B: Severely infected leaf of Vitis vinifera 'Rizamat': (A) upper and (B) lower surface of the same leaf. Sporangia are visible only on the lower surface.

C-F: Lower side of fully expanded leaves of (C) Vitis labruscana 'Campbell Early,' (D) V. vinifera 'Muscat of Alexandria,' and their descendants, (E) AC33, and (F) AC35. Insets show magnified views.

$\mathrm{G}, \mathrm{H}$ : Leaf discs of expanding leaves of $(\mathrm{G})$ 'Campbell Early' and (H) 'Muscat of Alexandria.' Upper images show discs inoculated with DM sporangia suspension one day after inoculation. Lower images show the same discs six days after inoculation. Note that $(G)$ no sporangia emerged on the discs with dense leaf trichomes, whereas (H) sporangia almost exactly matched the coverage of the inoculum (upper panel) on the discs with sparse trichomes. 


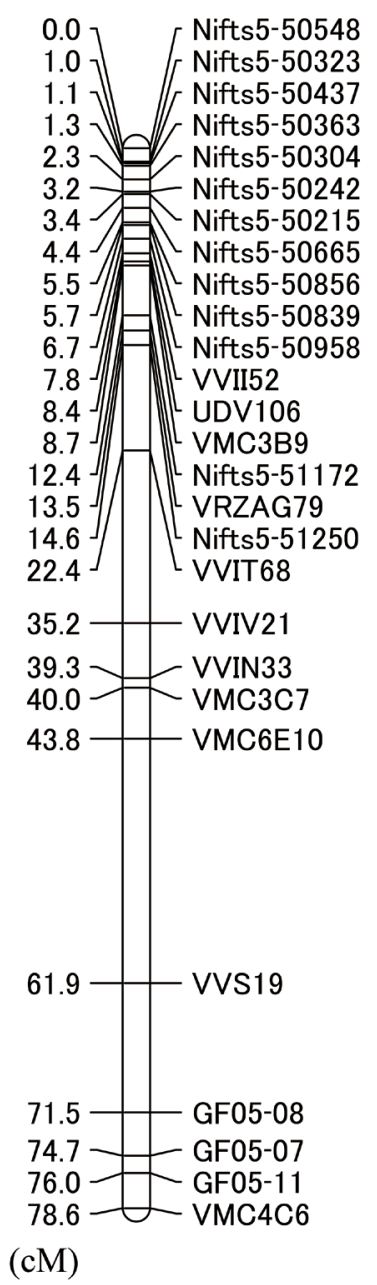

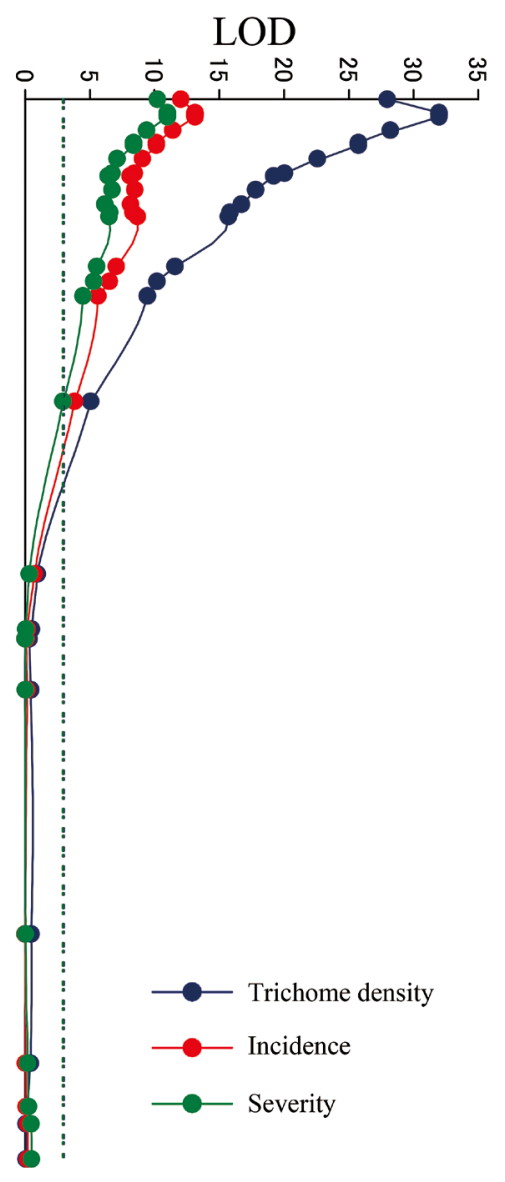

B

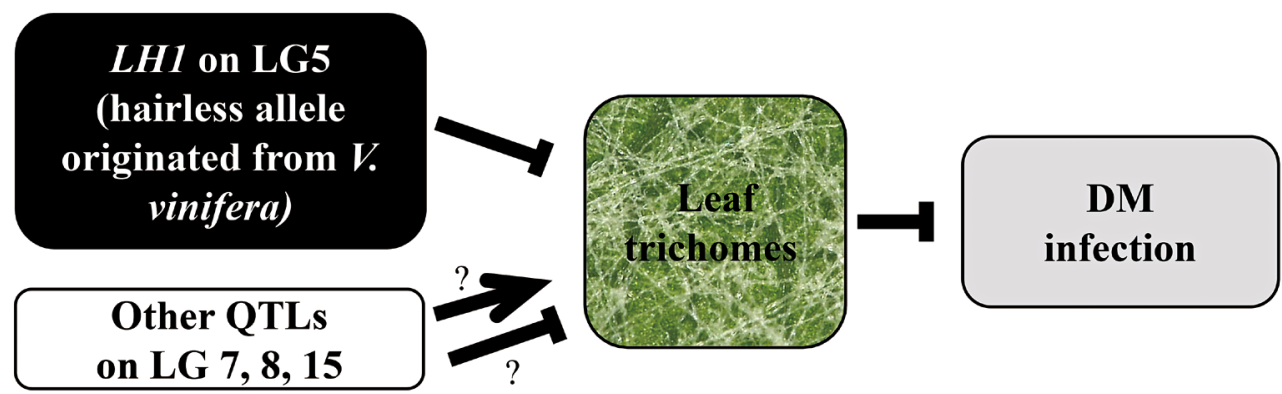

Fig. 2. Symptoms of grapevine downy mildew and underside leaf trichomes in grapevines

A: QTL-LOD profile of leaf hair density and downy mildew resistance traits in a population by crossing $V$. vinifera 'Muscat of Alexandria' and 'Campbell Early.' QTLs for downy mildew resistance (mean incidence and severity) under fungicide-free conditions and mean leaf trichome density on the 'Muscat of Alexandria' map are shown. Adapted by permission from Springer Nature Customer Service Centre GmbH: Springer Nature, Kono et al. (2018) Molecular Breeding, 38, 138.

B: Schematic diagram of interactions of QTLs for leaf trichome density and resultant downy mildew resistance in grapevines. 
were shown to have the hairless allele, which drastically reduces the density. A minor QTL was detected on LG 7 of 'Campbell Early' (Kono et al. 2018). A DM resistance locus with small effects (designated Rpv11) was identified on LG 5 (Fischer et al. 2004, Schwander et al. 2012). The relationship between $L H 1$ and nearby QTLs remains to be resolved. Figure $2 \mathrm{~B}$ shows a schematic diagram of interactions of QTLs for leaf trichome density and resultant DM resistance.

\section{Future perspectives}

In terms of the berry quality, $V$. vinifera table grape cultivars are preferable to $V$. labruscana. 'Muscat of Alexandria' and 'Katta Kurgan' are important old $V$. vinifera cultivars frequently used in Japanese table grape breeding (Yamada \& Sato 2016), but are susceptible to DM. Plasmopara viticola has already become resistant to some fungicides in Japan (Watauchi 2015), France, and Italy (Heaney et al. 2000). Furthermore, the partial resistance to DM in 'Regent' carrying the Rpv3 gene was overcome by some $P$. viticola isolates in less than five years in Europe (Delmotte et al. 2014). Even though the resistance conferred by trichomes cannot completely protect grapevines from DM, the dense trichome trait offers a feasible and promising mechanism for the sustainable control of DM in vineyards. If the trait is adopted as a breeding target, attention should be paid to avoid hairless alleles at the $L H I$ locus in breeding programs.

\section{References}

Agrios, G. (2005) Plant Pathology, 5th ed. Academic Press, Massachusetts, USA.

Arroyo-García, R. et al. (2006) Multiple origins of cultivated grapevine (Vitis vinifera L. ssp. sativa) based on chloroplast DNA polymorphisms. Mol. Ecol., 15, 3707-3714.

Bailey, L. H. \& Bailey, E. Z. (1930) Hortus, a concise dictionary of gardening, general horticulture and cultivated plants in North America. The Macmillan Company, New York, USA.

Barba, P. et al. (2019) A QTL associated with leaf trichome traits has a major influence on the abundance of the predatory mite Typhlodromus pyri in a hybrid grapevine population. Hort. Res., 6, 87.

Delmotte, F. et al. (2014) Rapid and multiregional adaptation to host partial resistance in a plant pathogenic oomycete: evidence from European populations of Plasmopara viticola, the causal agent of grapevine downy mildew. Infect. Genet. Evol., 27, 500-508.

Divilov, K. et al. (2017) Computer vision for high-throughput quantitative phenotyping: a case study of grapevine downy mildew sporulation and leaf trichomes. Phytopathology, 107, 1549-1555.
Divilov, K. et al. (2018) Single and multiple phenotype QTL analyses of downy mildew resistance in interspecific grapevines. Theor. Appl. Genet., 131, 1133-1143.

Dürinig, H. (1980) Stomata frequency of leaves of Vitis species and cultivars. Vitis, 19, 91-98.

Eibach, R. \& Töpfer, R. (2014) Progress in grapevine breeding. Acta. Hort., 1046, 197-209

Fischer, B. M. et al. (2004) Quantitative trait locus analysis of fungal disease resistance factors on a molecular map of grapevine. Theor. Appl. Genet., 108, 501-515.

Gerrath, J. et al. (2015) Taming the wild grape. Springer, Cham, Switzerland.

Gilbert, L. E. (1971) Butterfly-plant coevolution: has Passiflora adenopoda won the selectional race with Heliconiine butterflies? Science, 172, 585-586.

Grassi, F. el al. (2003) Evidence of a secondary grapevine domestication centre detected by SSR analysis. Theor. Appl. Genet., 107, 1315-1320.

Hamaya, E. (1982) Trichome infection of the tea anthracnose fungus Gloeosporium theae-sinensis. JARQ, 16, 114-118.

Heaney, S. P. et al. (2000) Resistance to Fungicides in the QoISTAR Cross-Resistance Group: Current Perspectives. Proceeding of the BCPC International Congress-Pests and Diseases, 755-762.

Hollier, C. A. \& King, S. B. (1985) Effect of dew period and temperature on infection of seedling maize plants by Puccinia polysora. Plant Dis., 69, 219-220.

Hülskamp, M. (2004). Plant trichomes: a model for cell differentiation. Nat. Rev. Mol. Cell Biol., 5, 471.

Johnson, H. B. (1975). Plant pubescence: an ecological perspective. Bot. Rev., 41, 233-258.

Julius Kühn-Institut (2019) Table of loci for traits in grapevine. http://www.vivc.de/docs/dataonbreeding/20181001_ Table $\% 20$ of $\% 20$ Loci $\% 20$ for $\% 20$ Traits\%20in $\% 20$ Grapevine.pdf

Karabourniotis, G. et al. (1995) Trichome density and its protective potential against ultraviolet-B radiation damage during leaf development. Can. J. Bot., 73, 376-383.

Karabourniotis, G. et al. (2019) Protective and defensive roles of non-glandular trichomes against multiple stresses: structure-function coordination. J. For. Res. (Harbin), $1-12$.

Kim, K. W. (2019) Plant trichomes as microbial habitats and infection sites. Eur. J. Plant Pathol., 154, 157-169.

Kono, A. et al. (2018) Development of SSR markers linked to QTL reducing leaf hair density and grapevine downy mildew resistance in Vitis vinifera. Mol. Breed., 38, 138.

Kortekamp, A. \& Zyprian, E. (1999) Leaf hairs as a basic protective barrier against downy mildew of grape. $J$. Phytopathol., 147, 453-459.

Kortekamp, A. et al. (1999) The role of hairs on the wettability of grapevine (Vitis spp.) leaves. Vitis, 38, 101-105.

Lafon, R. \& Bulit, J. (1981) Downy mildew of the vine. In Spencer DM (ed) The downy mildews. Academic Press, London, UK, pp. 601-614.

Łaźniewska, J. et al. (2012) Plant-fungus interface: the role of surface structures in plant resistance and susceptibility to pathogenic fungi. Physiol. Mol. Plant Pathol., 78, 24-30.

Levin, D. A. (1973) The role of trichomes in plant defense. $Q$. Rev. Biol., 48, 3-15.

Ma, Z. Y. et al. (2016) Morphology, Structure, and Ontogeny of 
Trichomes of the Grape Genus (Vitis, Vitaceae). Front. Plant. Sci., 7, 704.

Milli, A. et al. (2012) Proteomic analysis of the compatible interaction between Vitis vinifera and Plasmopara viticola. J. Proteomics., 75, 1284-1302.

Muganu, M. \& Paolocci, M. (2013) Adaptation of local grapevine germplasm: exploitation of natural defence mechanisms to biotic stresses. In Sladonja, B. \& Poljuha, D. (eds.) The Mediterranean Genetic Code - Grapevine and Olive, IntechOpen Limited, London, UK, pp. 221-246.

Olmo, H. P. (1976) Grapes. In Simmounds, N. W. (ed.) Evolution of crop plants, Longman, London, UK, pp. 294-298.

Poos, F. W. (1929) Leafhopper injury to legumes. J. Econ. Entomol., 22, 146-153.

Poos, F. W. \& Smith, F. F. (1931) A comparison of oviposition and nymphal development of Empoasca fabae Harris on different host plant. J. Econ. Entomol., 84, 361-371.

Reisch, B. I. \& Pratt, C. (1996) Grapes. In Janick, J. \& Moore J. N. (eds.) Fruit Breeding, Volume II: Vine and Small Fruits, Wiley \& Sons, Inc., New York, USA, pp. 297-369.

Reisch, B. I. et al. (2012) Grape. In Badenes, M. \& Byrne, D. H. (eds.) Fruit Breeding, Springer, Berlin, pp. 225-262

Reynolds, K. M. et al. (1989) Splash dispersal of Phytophthora cactorum from infected strawberry fruit by simulated canopy drip. Phytopathology, 79, 425-432.

Schwander, F., et al. (2012) Rpv10: a new locus from the Asian
Vitis gene pool for pyramiding downy mildew resistance loci in grapevine. Theor. Appl. Genet., 124, 163-176.

Shaik, M. (1985) Race nonspecific resistance in bean cultivars to race of Uromyces appendiculatus var. appendiculatus and its correlation with leaf epidermal characteristics. Phytopathology, 75, 478-481.

Shimizu, T. et al. (2019) Transcriptional analysis of defenserelated genes induced by infection with the causal agent of downy mildew, Plasmopara viticola, in grapevine cultivar Shine Muscat. J. Gen. Plant Pathol., 85, 182-188.

Staudt, G. \& Kassemeyer, H. H. (1995) Evaluation of downy mildew resistance in various accessions of wild Vitis species. Vitis, 34, 225-228.

Watauchi, K. et al. (2015) Occurrence of QoI Fungicideresistant Strains of Plasmopara viticola, in Yamanashi Prefecture. Yamanashi-ken Kajushikenjo Houkoku (Bulletin of Yamanashi Fruit Tree Experiment Station), 14, 39-47 [In Japanese with English summary].

Yamada, K. \& Sonoda, R. (2014) A fluorescence microscopic study of the infection process of Discula theae-sinensis in tea. JARQ, 48, 399-402.

Yamada, M. \& Sato, A. (2016) Advances in table grape breeding in Japan. Breed. Sci., 66, 34-45.

Zaiter, H. Z. et al. (1990) Inheritance of abaxial leaf pubescence in beans. J. Am. Soc. Hort. Sci., 115, 158-160. 